\title{
MANAJEMEN RISIKO RANTAI PASOK PRODUK SAYURAN MENGGUNAKAN METODE SUPPLY CHAIN OPERATION REFERENCE DAN MODEL HOUSE OF RISK
}

\author{
Andi Haifa Kania Nadhira ${ }^{1)}$, Teguh Oktiarso ${ }^{2)}$, Titik Desy Harsoyo ${ }^{3)}$ \\ 1) 2) Teknik Industri Universitas Machung, Jl. Villa Puncak Tidar Blok N-1 Malang \\ ${ }^{3)}$ Manajemen Universitas Mercu Buana, Jl. Wates KM 10 Yogyakarta \\ email : kania2806@gmail.com ${ }^{1)}$, teguh.oktiarso@machung.ac.id ${ }^{2)}$,desycapry@yahoo.com 3'
}

\begin{abstract}
Abstraksi
Pada proses distribusi hasil pertanian di Kabupaten Malang, masih sering ditemukan beberapa masalah. Salah satunya adalah adanya kesulitan dalam melakukan penjualan produk pertanian secara maksimal. Proses distribusi ini adalah bagian dari operasi rantai pasok, yang pengelolaannya menjadi sangat penting. Dibutuhkan langkah identifikasi dan analisis risiko untuk menemukan potensi risiko yang timbul dari setiap masalah agar hambatan dan kerugian yang terjadi dapat diantisipasi.Penelitian terhadap manajemen risiko pada rantai pasok hasil pertanian ini dilaksanakan dengan menggunakan metode Supply Chain Operation Reference (SCOR) dalam mengidentifikasi risiko beserta agen risikonya, serta menggunakan model House Of Risk (HOR) untuk menganalisis risiko yang terjadi, untuk kemudian menentukan strategi mitigasi atas risiko tersebut.Hasil yang diperoleh pada penelitian rantai pasok distribusi produk sayuran di STA Mantung Kabupaten Malang adalah ditemukannya 15 risiko dan 23 agen risiko. Dari 23 agen risiko ini, terpilih 12 agen risiko utama yang dipilih dan dianalisis untuk kemudian ditentukan strategi mitigasi risiko yang tepat untuk diterapkan.Strategi mitigasi yang diperoleh pada penelitian ini adalah sebanyak 14 strategi mitigasi.Dengan adanya pengelolaan risiko dan strategi mitigasi pada rantai pasok distribusi, diharapkan STA Mantung Kabupaten Malang lebih siap dalam menghadapi risiko yang terjadi.
\end{abstract}

\section{Kata Kunci :}

Produk Pertanian, Manajemen Risiko, SCOR, HOR

\begin{abstract}
In the distribution process of the agricultural products in Malang Regency, there still many problems be found. One of them is the difficulty in gaining the maximum sales of the agricultural products. Distribution process is part of a supply chain operation, of which its management is very important. Identification steps and risks analysis are required to find the potential risks arise from every problem, in order to anticipate the barriers and losses occurred. This research on risk management in the supply chain of agricultural products is implemented by using the Supply Chain Operation Reference (SCOR) method in identifying risks and their risk agents, and by using the House of Risks (HOR) method in analyzing every risk that occur, then to determine the mitigation strategies for those risks. Results obtained from this research of supply chain distribution of vegetable products at STA Mantung, Malang Regency, is the discovery of 15 risks with 23 risk agents. From these 23 risk agents, 12 major risk agents were selected and analyzed to determine the appropriate risk mitigation strategies to be applied. Mitigation strategies obtained from this study are 14 mitigation strategies. With the existence of risk management and mitigation strategy in the supply chain distribution, it is expected that STA Mantung, Malang Regency shall be better prepared to facing the risks those occurred.
\end{abstract}

Keywords :

Agricultural products, Risk Management, SCOR, HOR 


\section{PENDAhUluan}

Indonesia merupakan negara agraris yang memiliki hasil pertanian dan perkebunan yang melimpah. Terdapat banyak sekali daerah di Indonesia yang menjadi daerah penghasil pertanian. Pada provinsi Jawa Timur, Kabupaten Malang adalah salah satu kabupaten yang menjadi produsen produk hasil pertanian ke berbagai daerah. Hasil pertanian dari Kabupaten Malang adalah beras, sayur-mayur, umbi-umbian, dan buah-buahan. Beberapan kecamatan yang menjadi produsen utama di Kabupaten Malang adalah kecamatan Dau, Poncokusumo, dan Pagelaran

Sebagai salah satu produsen, para petani, pedagang maupun pemasok, harus menjalankan proses distribusi yang baik secara merata. Hasil pertanian Kabupaten Malang didistribusi ke berbagai daerah di Indonesia, baik dalam Kabupaten Malang sendiri, hingga di luar provinsi Jawa Timur. Namun, dalam melakukan proses distribusi hasil pertanian masih sering ditemukan beberapa masalah. Salah satunya adalah beberapa daerah di Kabupaten Malang kesulitan melakukan penjualan secara maksimal untuk produk pertanian mereka. Oleh karena itu, proses distribusi hasil pertanian ini dianggap masih kurang maksimal mengingat hal ini masih terjadi pada proses distribusi.

Proses distribusi ini termasuk dalam rantai pasok distribusi pertanian di Kabupaten Malang. Pengolaaan rantai pasok ini adalah hal yang penting dari sebuah proses distribusi. Pengelolaan rantai pasok dari petani, yakni produsen utama, pemasok, pedagang, hingga sampai ke tangan konsumen membutuhkan manjemen yang baik dan tepat. Dikarenakan masih sering ditemukan masalah pada rantai pasok distribusi hasil pertanian di Kabupaten Malang, dibutuhkan identifikasi dan analisis risiko untuk menemukan risiko yang ditimbulkan dari setiap masalah yang ada agar dapat mengantisipasi kerugian dan hambatan yang dapat ditimbulkan. Pengelolaan dan analisis risiko rantai pasok ini diartikan sebagai manajemen rantai pasok. Manajemen rantai pasok ini mampu menemukan penyebab dari masalah yang ditimbulkan melalui proses identifikasi dan analisis proses distribusi. Setelah dilakukan analisis, akan ditemukan strategi yang tepat untuk memaksimalkan rantai pasok distribusi, dalam kasus ini adalah distribusi produk hasil pertanian produk sayuran di Kabupaten Malang.

Penelitian kali ini ditujukkan untuk meneliti risiko yang ada terhadap setiap keputusan yang diambil pada rantai pasok distribusi produk hasil pertanian di Kabupaten Malang agar dapat meminimalisir masalah yang akan timbul hingga penyebab dari setiap masalah. Penelitian ini dilakukan pada Unit Pelaksana Teknis (UPT) Sub Terminal Agribisnis (STA) Mantung, Pujon, Kabupaten Malang. Hal ini dikarenakan proses keluar-masuk atau jual-beli, hingga distrbusi dilakukan oleh para pelaku rantai pasok hortikultura jenis sayuran pada UPT STA Mantung. Pada penelitian kali ini digunakan metode Supply Chain Operation Reference (SCOR) untuk mengidentifikasi risiko yang ada pada faktor tertentu, yakni plan, source, make, deliver, dan return. Setelah menemukan risiko yang berpotensi, maka akan dilakukan penilaian terhadap risiko yang berpotensi. Penilaian risiko ini dilakukan dengan metode House of Risk (HOR). Setelah melakukan analisis risiko dengan menggunakan kedua metode diatas, akan dapat dilakukan rancangan strategi mitigasi untuk rantai pasok distribusi produk 
hasil pertanian di Kabupaten Malang agar lebih siap menghadapi masalah-masalah yang akan timbul seiring berjalannya waktu.

\section{TINJAUAN PUSTAKA}

2.1 Risiko

Menurut KBBI, risiko adalah akibat yang kurang menyenangkan dari suatu perbuatan atau tindakan. Risiko adalah sebuah kemungkinan dari suatu kejadian yang dapat mengakibatkan kerugian jika terjadi selama periode tertentu [1]. Selain itu, risiko juga dapat diartikan sebagai ketidakpastian yang membawa dampak pada tujuan utama [2]. Sumber utama dari risiko pada adalah ketidakpastian. Ketidakpastian inilah yang memunculkan risiko [3]. Maka, secara garis besar, risiko adalah kemungkinan dari suatu kerjadian yang dapat membawa dampak pada tujuan utama selama selang waktu tertentu. Risiko dapat berupa kerugian kecil yang tidak begitu berarti, hingga kerugian besar yang membawa dampak yang besar baik materil, maunpun non materil.

\subsection{Rantai Pasok}

Rantai pasok adalah hubungan atau alur proses sebuah barang ataupun jasa dari tahap penyediaan bahan baku hingga produk akhir yang sampai di tangan konsumen. Pada rantai pasok terdapat hubungan antara barang atau jasa, uang, dan informasi. Menurut Zsidisin dan Ritchie [4], rantai pasok terdiri dari semua pihak yang terlibat secara langsung maupun tidak langsung dalam memenuhi permintaan pelanggan. Rantai pasok tidak hanya mencakup produsen dan pemasok, tapi juga penyangkut gudang, pengecer, dan bahkan pelanggan sendiri. Berdasarkan paparan tersebut, rantai pasok memiliki lima komponen dalam arus binisnya, yakni pemasok (supplier), pabrik (manufacturer), distributor, pengecer (retailer), dan pelanggan (customer). Rantai pasok mencakup semua fungsi yang terlibat dalam penerimaan dan pemenuhan permintaan pelanggan. Permintaan ini dapat meliputi pengembangan produk baru, pemasaran, operasi, distribusi, keuangan, hingga pelayan pelanggan [4].

\subsection{Manajemen Risiko Rantai Pasok}

Manajemen risiko dan manajemen rantai pasok adalah dua hal yang saling berkaitan. Manajemen risiko rantai pasok adalah upaya pengelolaan risiko-risiko yang dapat terjadi pada sebuah aktivitas rantai pasok agar didapatkan rantai pasok yang optimal dan tercegah dari gangguan. Manajemen risiko rantai pasok menjadi isu penting dan memerlukan perhatian yang serius, hal ini dikarenakan dampak risiko yang sering terjadi, dan potensi dampak signifikan terhadap kinerja para pelaku rantai pasok [5]. Pada manajemen risiko rantai pasok terdapat karakteristik dari risiko rantai pasok, yaitu memfokuskan pada aspek-aspek yang perlu diperhatikan karena dapat membuat dampak yang berkesinambungan. 


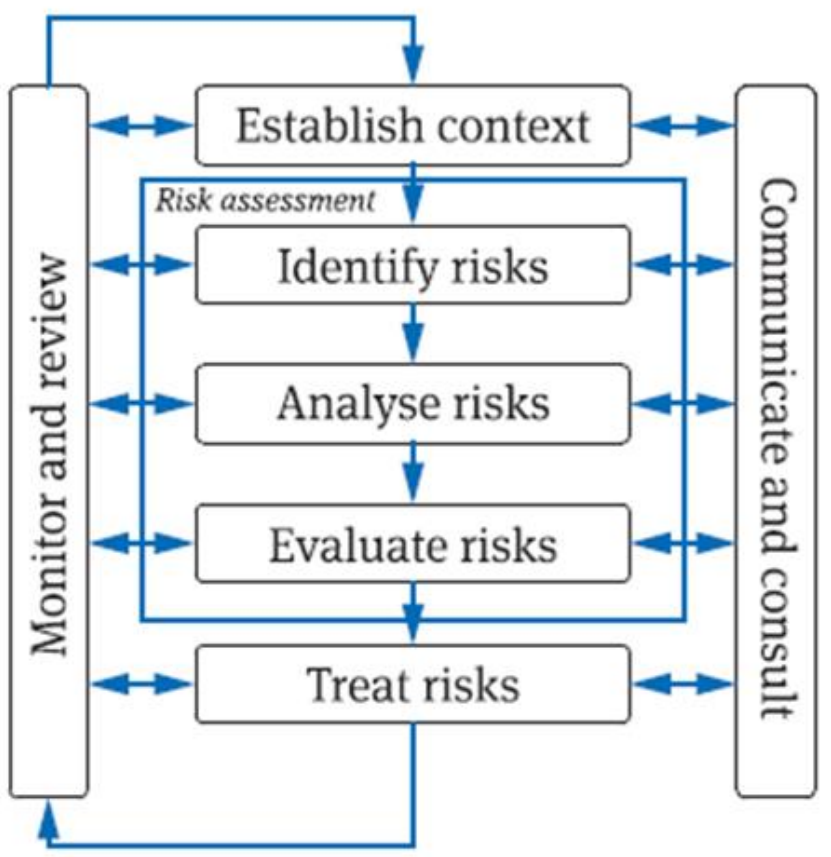

Gambar 1 Tahapan Manajemen Risiko (ISO, 2015)

Proses rantai pasok akan terjadi apabila dipicu oleh aliran informasi dari berbagai pihak atau pelaku rantai pasok dalam bentuk permintaan. Pada kenyataannya, keterbatasan informasi dan pengetahuan maupun kendala dari setiap fungsi di dalam sistem rantai pasok mengakibatkan munculnya ketidakpastian [6].

\subsection{Metode Supply Chain Operation Reference (SCOR)}

Metode Supply Chain Operation Reference (SCOR) adalah metode pendekatan untuk melakukan pengukuran kinerja rantai pasok, dalam arti lain, metode ini digunakan untuk melakukan manajemen rantai pasok. Metode SCOR yang digunakan adalah level 1, yakni mendefinisikan ruang lingkup dan dan konten dari rantai pasok tersebut. Pada level ini akan terlihat kinerja dari rantai pasok. Manajemen rantai pasok dengan menggunakan metode SCOR dibagi menjadi beberapa bagian rantai pasok, yaitu perencanaan (plan), pengadaan (source), pembuatan (make), pengiriman (deliver), dan pengembalian (return) [7]. Berikut ini adalah fungsi dari masing-masing pembagian rantai pasok [7]:

- Perencanaan (Plan)

Bagian ini menggambarkan kegiatan yang terkait dengan pengembangan rencana untuk mengoperasikan rantai pasokan.

- Pengadaan (Source)

Bagian ini menggambarkan pemesanan, penjadwalan, pengiriman dan penerimaan barang hingga pelayanan yang diterima.

- Pembuatan (Make) 
Menggambarkan aktivitas yang terkait dengan konversi bahan atau pembuatan konten atau produk rantai pasok.

- Pengiriman (Deliver)

Menggambarkan proses pemenuhan permintaan barang atau jasa dari rantai pasok

- Pengembalian (Return)

Menggambarkan kegiatan yang terkait dengan arus balik barang atau penerimaan kembali barang atau produk dengan berbagai alasan.

\subsection{Metode House of Risk (HOR)}

Metode House of Risk adalah model pengelolaan risiko dari hasil pengembangan dan modifikasi dari model HOQ yang berfungsi untuk menentukan agen risiko, dan penentuan prioritas dalam melakukan pencegahan [8].

Berikut ini adalah urutan langkah HOR fase pertama [8]:

- Mengidentifikasi risiko-risiko yang berpotensi pada rantai pasok. Risiko yang teridentifikasi digolongkan pada setiap proses bisnis dengan menggunakan SCOR.

- Mengidentifikasi agen risiko yang menyebabkan terjadinya risiko yang sebelumnya teidentifikasi.

- Mengidentifikasi dampak yang akan ditimbulkan dari risiko yang terjadi (severity). Selanjutnya, memberikan nilai tingkat keparahan yang risiko yang terjadi.

- Memberi penilaian kemungkinan terjadinya (occurrence) dari agen risiko.

- Memberi penilaian korelasi antara masing-masing kejadian risiko antara masingmasing risiko yang teridentifikasi dengan agen risiko.

- Melakukan perhitungan ARP dengan menggunakan data severity, occurrence, dan nilai korelasi yang sebelumnya telah ditentukan.

- Memberikan peringkat pada masing-masing agen risiko yang teridentifikasi sesuai dengan nilai ARP yang sebelumnya telah dihitung. Peringkat ini diberikan sesuai urutan nilai terbesar hingga terkecil.

Tabel 1 HOR Fase 1 (Pujawan dan Geraldine, 2009)

\begin{tabular}{cccccc}
\hline \multirow{2}{*}{ Proses bisnis } & Risiko & \multicolumn{3}{c}{ Agen Risiko } & \multirow{2}{*}{ Severity } \\
\cline { 3 - 5 } & $(\mathrm{Ei})$ & $\mathrm{A} 1$ & $\mathrm{~A} 2$ & $\mathrm{~A} 3$ & \\
\hline Plan & $\mathrm{E} 1$ & $\mathrm{R} 11$ & $\mathrm{R} 12$ & $\mathrm{R} 13$ & $\mathrm{~S} 1$ \\
Source & $\mathrm{E} 2$ & $\mathrm{R} 21$ & & & S2 \\
Make & E3 & & & & S3 \\
Deliver & E4 & & & S4 \\
Return & E5 & & & S5 \\
\hline Occurrence $\left(\mathrm{O}_{\mathrm{i}}\right)$ & & O1 & O2 & O3 & \\
\hline ARP & & ARP1 & ARP2 & ARP3 & \\
\hline
\end{tabular}


URL : https://jurnal.machung.ac.id/index.php/kurawal

Tabel 2 Model HOR Fase 2 (Pujawan dan Geraldine, 2009)

\begin{tabular}{cccc}
\hline \multirow{2}{*}{ Agen risiko } & \multirow{2}{*}{ ARP } & \multicolumn{2}{c}{ Strategi Mitigasi } \\
\cline { 3 - 4 } & & SMl & SM2 \\
\hline A1 & ARP1 & F11 & F12 \\
A2 & ARP2 & & \\
A3 & ARP3 & & \\
A4 & ARP4 & & \\
Total Efehtifitas Strategi & TE1 & TE2 \\
Tingkat Kesulitan Strategi & D1 & D2 \\
Total Efeltifitas Rasio Kesulitan & ETD1 & ETD2 \\
Peringkat Prioritas Strategi Mitigasi & & \\
\hline
\end{tabular}

Setelah melakukan model HOR fase pertama sebanyak tujuh langkah, langkah selanjutnya adalah membuat model HOR fase kedua. Berikut ini adalah tabel model HOR fase kedua:

- Memilih agen risiko dengan peringkat atau penilaian tertinggi menggunakan diagram pareto.

- Mengidentifikasi strategi mitigasi yang tepat dengan menggunakan diagram Ishikawa untuk masing-masing agen risiko yang telah dipilih sebelumnnya.

- Memberi penilaian korelasi antara agen risiko yang telah dipilih dengan strategi mitigasi.

- Melakukan perhitungan efektifitas dari masing-masing strategi yang telah ditentukan.

- Memberi peringkat kesulitan untuk setiap strategi mitigasi yang telah ditentukan

- Melakukan perhitungan total efektivitas rasio kesulitan yang dinotasikan sebagai ETDk.

- Memberi peringkat terhadap masing-masing strategi mitigasi berdasarkan nilai ETDk yang sebelumnya telah dihitung, dari nilai terbesar hingga terkecil.

\subsection{Diagram Pareto}

Diagram pareto adalah salah satu jenis diagaram yang terdiri dari grafik berbentuk balok dan garis. Penamaannya sendiri diambil dari nama orang yang menemukannya yaitu Vilfredo Pareto. Diagram pareto menggambarkan $80 \%$ masalah yang ada disebabkan oleh $20 \%$ penyebab yang ada. Pada dasarnya, diagram pareto menujukkan pengaruh dari sebuah masalah diagram pareto juga dapat digunakan untuk mengidentifikai beberapa peluang untuk perbaikan dari masalah tersebut. Diagram pareto menunjukan manakah masalah yang terlebih dahulu harus diperbaiki [9]. 


\subsection{Diagram Fishbone}

Diagram fishbone atau sering juga disebut sebagai diagram Ishikawa dan diagram sebab akibat adalah diagram yang digunakan untuk mengetahui kemungkinan penyebab suatu masalah bisa terjadi. Diagram fishbone diperkenalkan oleh Dr. Kaoru Ishikawa, seorang ahli pengendalian kualitas dari Jepang, sebagai satu dari tujuh alat kualitas dasar (7 basic quality tools).

\subsection{Tujuan dan Manfaat}

\subsubsection{Tujuan}

Tujuan dilakukannya penelitian ini adalah mengidentifikasi risiko pada proses distribusi produk sayuran di Kabupaten Malang dengan menggunakan metode SCOR, melakukan penilaian risiko rantai pasok, menemukan faktor-faktor penyebab risiko, menentukan rancangan strategi mitigasi risiko yang tepat dengan menggunakan metode HOR pada risiko yang ada pada distribusi produk sayuran di UPT STA Mantung.

\subsubsection{Manfaat}

Manfaat dari penelitian ini adalah dapat membantu stakeholder pada instansi UPT STA Mantung untuk mengidentifikasi dan menilai risiko yang dapat terjadi dari proses distribusi. Selain itu, para pelaku rantai pasok juga dapat menentukan prioritas dan merancang strategi mitigasi yang tepat dan optimal untuk menghindari masalah yang dapat terjadi.

\section{METODE / ALGORITMA}

Pada penelitian ini, lokasi pengambilan data distribusi produk pertanian di Kabupaten Malang adalah di ub Terminal Agrobisnis (STA) Manrung yang terletak di Ngantang, Pujon. Pengambilan data serta wawancara kepada para pelaku distribusi produk pertanian berlangsung dari Maret hingga Mei 2018.

Data yang diambil dari STA Mantung adalah sebagai berikut :

a. Data Primer

Data primer adalah data utama yang digunakan pada pengolahan data penelitian. Data ini diambil dari hasil pengamatan secara langsung dan analisis penulis. Metode yang digunakan untuk pengambilan data primer ini adalah pengamatan secara langsung, wawancara, diskusi, dan kuesioner atau form penilaian yang diberikan pada pelaku rantai pasok. Data primer ini berwujud aktivitas rantai pasok, sumber risiko, kejadian risiko, dan penilaian risiko.

b. Data Sekunder

Data sekunder ini adalah data yang didapatkan dari pelaku rantai pasok pada proses distribusi sayuran di UPT STA Mantung Kabupaten Malang. Metode yang digunakan untuk pengambilan data sekunder adalah studi dokumenter, yakni membaca dokumen-dokumen perusahaan terkait data yang dibutuhkan dalam pengolahan data. Data sekunder ini berwujud data supplier, data produksi atau panen petani, data penjadwalan, dan sebagainya. 
Sedangkan proses pengambilan data primer maupun sekunder, dilakukan prosedur sebagai berikut :

a. Studi Lapangan

Metode ini dilakukan dengan cara pengamatan atau observasi secara langsung di UPT STA Mantung, Pujon, Kabupaten Malang.

b. Wawancara

Metode ini dilakukan dengan cara melakukan wawancara in-depth, yaitu dengan melakukan tanya jawab sambil bertatap muka dengan narasumber atau pelaku rantai pasok untuk memperoleh informasi.

c. Form Penilaian

Metode ini dilakukan dengan cara memberikan kuesioner atau form penilaian untuk severity, occurrence, dan korelasi terhadap risiko yang ditemukan. Form penilaian ini diberikan kepada pada pelaku rantai pasok proses distribusi sayuran di UPT STA Mantung Kabupaten Malang. Form penilaian ini menggunakan skala peringkat dari yang paling tinggi hingga paling rendah, atau sebaliknya.

\section{HASIL DAN PEMBAHASAN}

Langkah awal dalam melakukan manajemen risiko adalah mengidentifikasi risiko yang terjadi pada rantai pasok distribusi di STA Mantung Kabupaten Malang. Penelitian kali ini difokuskan terhadap rantai pasok distribusi pada pelaku pedagang atau pengepul desa di STA Mantung Kabupaten Malang.

Tabel 3 Risiko Rantai Pasok dan Penilaian Severity

\begin{tabular}{|c|c|c|c|}
\hline Elemen SCOR & Kode & Risiko & Severity \\
\hline \multirow{3}{*}{ Perencanaan (Plan) } & E1 & Kenaikan harga sayuran dari produsen utama & 8 \\
\hline & E2 & Keuntungan pengepul/pedagang berkurang & 6 \\
\hline & E3 & Ketidaksesuaian jenis sayuran yang dipesan & 5 \\
\hline \multirow{2}{*}{$\begin{array}{l}\text { Pengadaan } \\
\text { (Source) }\end{array}$} & E4 & Ketidaksesuaian kualitas sayur yang dipesan & 5 \\
\hline & E5 & Jumlah sayuran yang terlalu banyak & 5 \\
\hline \multirow{6}{*}{ Pembuatan (Make) } & E6 & Terdapat sayuran yang rusak & 6 \\
\hline & E7 & Penyusutan kuantitas dan kualitas sayuran & 4 \\
\hline & E8 & Penurunan kualitas sayuran akibat packaging & 4 \\
\hline & E9 & Pembatalan pesanan & 8 \\
\hline & E10 & Banyaknya pengepul atau pedagang & 7 \\
\hline & E11 & Banyaknya sayur yang terbuang & 8 \\
\hline \multirow{4}{*}{$\begin{array}{c}\text { Pengiriman } \\
\text { (Deliver) }\end{array}$} & E12 & Penurunan kualitas karena proses pengiriman & 3 \\
\hline & E13 & Kesalahan jenis atau jumlah sayur yang dikirim & 4 \\
\hline & E14 & Kendaraan pengalami kerusakan & 8 \\
\hline & E15 & Keterlambatan pengiriman & 6 \\
\hline
\end{tabular}


Proses pengumpulan data untuk mengidentifikasi risiko-risiko di STA Mantung Kabupaten Malang dilakukan dengan dua cara, yaitu, studi lapangan dan wawancara. Studi lapangan dilakukan untuk pengobservasi keadaan atau masalah yang sering terjadi. Penilaian severity ini dilakukan untuk mengetahui pengaruh atau tingkat keparahan yang diakibatkan oleh risiko-risiko tersebut. Penilaian severity ini dilakukan dengan skala 1-10. Skala 1 adalah tidak ada pengaruh sama sekali, sedangkan skala 10 adalah berbahaya tanpa peringatan, yang artinya dampak tersebut terjadi tiba-tiba atau sewaktu-waktu. Tabel 3 menunjukkan risikorisiko yang teridentifikasi dan penilaian Severity.

Langkah selanjutnya adalah identifikasi agen risiko dilakukan untuk mengetahui penyebabpenyebab risiko yang berpotensi terjadi pada rantai pasok. Identifikasi risiko dibutuhkan untuk dilakukannya analisis terhadap penyebab-penyebab risiko. Analisis risiko ini nantinya akan menghasilkan sebuah strategi mitigasi untuk mengurangi, menghindari, memindahkan, bahkan menghilangkan risiko.

Tabel 4 Agen Risiko dan Penilaian Occurrence

\begin{tabular}{|l|l|c|}
\hline Kode & \multicolumn{1}{|c|}{ Agen Risiko } & Occurrence \\
\hline AR1 & Permintaan meningkat & 7 \\
\hline AR2 & Jumlah menyusut & 6 \\
\hline AR3 & Gagal panen & 2 \\
\hline AR4 & Permintaan tidak berkurang dan bertambah & 6 \\
\hline AR5 & Faktor alam atau bencana & 1 \\
\hline AR6 & Perjalanan macet atau tersendat & 7 \\
\hline AR7 & Kurang layaknya transportasi atau kendaraan & 4 \\
\hline AR8 & Sayur rusak dalam perjalanan & 4 \\
\hline AR9 & Kesalahan penyimpanan & 8 \\
\hline AR10 & Kesalahan packaging & 6 \\
\hline AR11 & Penundaan jadwal pengiriman & 5 \\
\hline AR12 & Kondisi suatu daerah yang tidak kondusif & 1 \\
\hline AR13 & Manajemen pengepul atau pedagang kurang terorganisir & 4 \\
\hline AR14 & Jumlah petani yang meningkat & 2 \\
\hline AR15 & Kualitas sayur yang tidak sesuai & 7 \\
\hline AR16 & Teknik pengecekan kualitas sayur & 7 \\
\hline AR17 & Jenis transportasi atau kendaraan & 4 \\
\hline AR18 & Jumlah permintaan yang tidak tercatat & 8 \\
\hline AR19 & Informasi pembeli yang kurang jelas & 6 \\
\hline AR20 & Human error & 4 \\
\hline AR21 & Keterbatasan sumber daya (tools) & 4 \\
\hline AR22 & Ketidakpastian pesanan & 5 \\
\hline AR23 & Teknik perlakuan atau penanganan sayuran kurang maksimal & 4 \\
\hline
\end{tabular}


Setelah menemukan risiko-risiko yang berpotensi terjadi, langkah selanjutnya adalah melakukan penilaian occurrence atau kemungkinan terjadinya agen risiko tersebut. Penilaian occurrence ini dilakukan dengan skala 1-10, dengan skala 1, yaitu hampir tidak pernah terjadi, sedangkan 10, yaitu hampir pasti pernah terjadi. semakin kecil nilai occurrence pada agen risiko rantai pasok distribusi STA Mantung Kabupaten Malang, maka semakin kecil kemungkinan terjadinya penyebab risiko-risiko rantai pasok distribusi, begitupun sebaliknya. Tabel 4 menunjukkan Risiko dan Penilaian Occurrence dari penelitian ini.

Langkah selanjutnya pada manajemen risiko rantai pasok adalah melakukan penilaian korelasi antara risiko dengan agen risiko. Penilaian korelasi ini bertujuan untuk mengetahui hubungan antara risiko dengan agen penyebab risiko. Hubungan antara risiko dan agen risiko ini perlu dianalisis karena setiap agen risiko dapat menyebabkan beberapa risiko, begitupun sebaliknya. Setelah mendapatkan penilain korelasi, maka langkah selanjutnya adalah perhitungan aggregate risk potential (ARP). Perhitungan ARP ini dilakukan untuk mengetahui besar potensi sebuah risiko dan masing-masing agen risiko yang dapat terjadi. Perhitungan ARP dilakukan dengan rumus pada rumus 2.1. Contoh perhitungan ARP pada AR1. AR1 memiliki nilai occurrence sebesar 7, dengan korelasi tinggi nilai 9 pada E1 dan E1, korelasi sedang nilai 3 pada E6, E7, dan E15, dan korelasi rendah nilai 1 pada E4, E8, E11, dan E12. Masingmasing korelasi akan dikalikan oleh nilai severity masing-masing risiko. Perhitungan ARP pada ARI adalah sebagai berikut:

$$
\begin{aligned}
A R P 1 & =7 x[(9 x 8)+(9 x 7)+(3 x 6)+(3 x 4)+(3 x 6)+5+4+8+3] \\
& =1421
\end{aligned}
$$

Setelah melakukan perhitungan ARP dengan hasil seperti diatas, langkah selanjutnya adalah mengurutkan peringkat agen risiko dengan nilai ARP terbesar hingga terkecil. Hal ini dilakukan agar mengetahui agen risiko dengan potensi yang paling besar dari agen-agen risiko lainnya. Tabel 5 adalah tabel peringkat ARP agen risiko.

Langkah selanjutnya adalah melakukan pengolahan data untuk HOR fase kedua. Langkah pertama dari HOR fase kedua adalah melakukan pemilihin agen risiko dengan menggunakan diagram pareto. Prinsip dari diagram pareto sendiri adalah $80 \%$ masalah atau gangguan disebabkan oleh $20 \%$ penyebab. Pemilihin agen risiko menggunakan diagram pareto ini dilakukan untuk mengetahui manakah agen rsiko yang terlebih dahulu harus dirancang strategi mitigasinya. 
URL : https://jurnal.machung.ac.id/index.php/kurawal

\begin{tabular}{ccc}
\multicolumn{3}{c}{ Tabel 5 Peringkat ARP } \\
\hline Agen & Nilai & \\
Risiko & ARP & Urutan \\
\hline ARP15 & 2156 & 1 \\
ARP2 & 1908 & 2 \\
ARP6 & 1820 & 3 \\
ARP9 & 1536 & 4 \\
ARP1 & 1421 & 5 \\
ARP10 & 1404 & 6 \\
ARP23 & 1280 & 7 \\
ARP20 & 1172 & 8 \\
ARP8 & 1056 & 9 \\
ARP22 & 1024 & 10 \\
ARP11 & 910 & 11 \\
ARP7 & 692 & 12 \\
ARP19 & 594 & 13 \\
ARP17 & 568 & 14 \\
ARP3 & 468 & 15 \\
ARP16 & 378 & 16 \\
ARP21 & 356 & 17 \\
ARP5 & 351 & 18 \\
ARP13 & 344 & 19 \\
ARP4 & 252 & 20 \\
ARP14 & 228 & 21 \\
ARP18 & 192 & 22 \\
ARP12 & 170 & 23 \\
\hline & &
\end{tabular}


URL : https://jurnal.machung.ac.id/index.php/kurawal

Tabel 6 HOR Fase 1

\begin{tabular}{|c|c|c|c|c|c|c|c|c|c|c|}
\hline \multirow{2}{*}{ Proses } & \multirow{2}{*}{ Risiko } & \multicolumn{8}{|c|}{ Agen Risiko } & \multirow[t]{2}{*}{ Severity } \\
\hline & & AR1 & AR2 & AR3 & AR4 & AR5 & AR6 & AR7 & AR8 & \\
\hline \multirow{3}{*}{ Plan } & E1 & 9 & 9 & 1 & 0 & 3 & 0 & 0 & 0 & 8 \\
\hline & E2 & 0 & 9 & 3 & 1 & 9 & 1 & 0 & 3 & 6 \\
\hline & E3 & 0 & 3 & 3 & 0 & 0 & 0 & 0 & 0 & 5 \\
\hline \multirow{2}{*}{ Source } & E4 & 1 & 3 & 9 & 0 & 9 & 3 & 0 & 9 & 5 \\
\hline & E5 & 0 & 0 & 0 & 3 & 0 & 0 & 0 & 0 & 5 \\
\hline \multirow{6}{*}{ Make } & E6 & 3 & 9 & 9 & 0 & 3 & 1 & 0 & 9 & 6 \\
\hline & E7 & 3 & 9 & 1 & 0 & 9 & 9 & 3 & 9 & 4 \\
\hline & E8 & 1 & 0 & 0 & 0 & 0 & 3 & 0 & 1 & 4 \\
\hline & E9 & 0 & 0 & 9 & 0 & 3 & 1 & 0 & 1 & 8 \\
\hline & E10 & 9 & 0 & 0 & 3 & 0 & 0 & 0 & 0 & 7 \\
\hline & E11 & 1 & 9 & 0 & 0 & 3 & 3 & 1 & 9 & 8 \\
\hline \multirow{4}{*}{ Deliver } & E12 & 1 & 0 & 0 & 0 & 9 & 9 & 9 & 9 & 3 \\
\hline & E13 & 0 & 0 & 0 & 0 & 0 & 0 & 0 & 0 & 4 \\
\hline & E14 & 0 & 0 & 0 & 0 & 9 & 9 & 9 & 0 & 8 \\
\hline & E15 & 3 & 0 & 3 & 0 & 9 & 9 & 9 & 0 & 6 \\
\hline \multicolumn{2}{|c|}{ Occurrence } & 7 & 6 & 2 & 6 & 1 & 7 & 4 & 4 & \\
\hline \multicolumn{2}{|c|}{ ARP } & 1421 & 1908 & 468 & 252 & 351 & 1820 & 692 & 1056 & \\
\hline \multicolumn{2}{|c|}{ Peringkat ARP } & 5 & 2 & 15 & 20 & 18 & 3 & 12 & 9 & \\
\hline
\end{tabular}

\begin{tabular}{|c|c|c|c|c|c|c|c|c|c|c|}
\hline \multirow{2}{*}{ Proses } & \multirow{2}{*}{ Risiko } & \multicolumn{8}{|c|}{ Agen Risiko } & \multirow[t]{2}{*}{ Severity } \\
\hline & & AR9 & AR10 & AR11 & AR12 & AR13 & AR14 & AR15 & AR16 & \\
\hline \multirow{3}{*}{ Plan } & E1 & 0 & 0 & 0 & 0 & 0 & 0 & 0 & 0 & 8 \\
\hline & E2 & 3 & 3 & 1 & 3 & 3 & 1 & 9 & 1 & 6 \\
\hline & E3 & 0 & 0 & 0 & 0 & 0 & 0 & 0 & 0 & 5 \\
\hline \multirow{2}{*}{ Source } & $\mathrm{E} 4$ & 3 & 9 & 1 & 1 & 0 & 0 & 9 & 3 & 5 \\
\hline & E5 & 0 & 0 & 0 & 0 & 1 & 9 & 0 & 3 & 5 \\
\hline \multirow{6}{*}{ Make } & E6 & 9 & 9 & 3 & 3 & 0 & 0 & 9 & 1 & 6 \\
\hline & E7 & 9 & 9 & 3 & 3 & 0 & 0 & 9 & 1 & 4 \\
\hline & E8 & 9 & 9 & 0 & 1 & 0 & 0 & 3 & 0 & 4 \\
\hline & E9 & 0 & 0 & 1 & 1 & 0 & 0 & 1 & 0 & 8 \\
\hline & E10 & 0 & 0 & 1 & 0 & 9 & 9 & 0 & 0 & 7 \\
\hline & E11 & 3 & 9 & 9 & 3 & 0 & 0 & 9 & 1 & 8 \\
\hline \multirow{4}{*}{ Deliver } & E12 & 3 & 3 & 0 & 9 & 0 & 0 & 9 & 0 & 3 \\
\hline & E13 & 0 & 0 & 0 & 0 & 0 & 0 & 0 & 0 & 4 \\
\hline & E14 & 0 & 0 & 0 & 0 & 0 & 0 & 0 & 0 & 8 \\
\hline & E15 & 0 & 0 & 9 & 9 & 0 & 0 & 0 & 0 & 6 \\
\hline \multicolumn{2}{|c|}{ Occurrence } & 8 & 6 & 5 & 1 & 4 & 2 & 7 & 7 & \\
\hline \multicolumn{2}{|c|}{ ARP } & 1536 & 1404 & 910 & 170 & 344 & 228 & 2156 & 378 & \\
\hline \multicolumn{2}{|c|}{ Peringkat ARP } & 4 & 6 & 11 & 23 & 19 & 21 & 1 & 16 & \\
\hline
\end{tabular}


URL : https://jurnal.machung.ac.id/index.php/kurawal

\begin{tabular}{|c|c|c|c|c|c|c|c|c|c|}
\hline \multirow{2}{*}{ Proses } & \multirow{2}{*}{ Risiko } & \multicolumn{7}{|c|}{ Agen Risiko } & \multirow[t]{2}{*}{ Severity } \\
\hline & & AR17 & AR18 & AR19 & AR20 & AR21 & AR22 & AR23 & \\
\hline \multirow{3}{*}{ Plan } & E1 & 0 & 0 & 0 & 0 & 0 & 0 & 1 & 8 \\
\hline & $\mathrm{E} 2$ & 0 & 0 & 0 & 3 & 1 & 9 & 3 & 6 \\
\hline & E3 & 0 & 1 & 3 & 9 & 0 & 0 & 0 & 5 \\
\hline \multirow{2}{*}{ Source } & $\mathrm{E} 4$ & 0 & 0 & 0 & 9 & 0 & 0 & 3 & 5 \\
\hline & E5 & 3 & 3 & 0 & 0 & 0 & 1 & 0 & 5 \\
\hline \multirow{6}{*}{ Make } & E6 & 1 & 0 & 0 & 3 & 3 & 3 & 9 & 6 \\
\hline & E7 & 1 & 0 & 0 & 3 & 3 & 3 & 9 & 4 \\
\hline & E8 & 1 & 0 & 0 & 9 & 9 & 1 & 9 & 4 \\
\hline & E9 & 0 & 0 & 9 & 1 & 0 & 9 & 1 & 8 \\
\hline & E10 & 0 & 0 & 0 & 0 & 0 & 0 & 0 & 7 \\
\hline & E11 & 1 & 0 & 0 & 3 & 1 & 9 & 9 & 8 \\
\hline \multirow{4}{*}{ Deliver } & E12 & 9 & 0 & 0 & 3 & 3 & 3 & 3 & 3 \\
\hline & E13 & 0 & 1 & 3 & 9 & 0 & 1 & 0 & 4 \\
\hline & E14 & 3 & 0 & 0 & 3 & 0 & 0 & 0 & 8 \\
\hline & E15 & 9 & 0 & 0 & 3 & 0 & 1 & 0 & 6 \\
\hline \multicolumn{2}{|c|}{ Occurrence } & 4 & 8 & 6 & 4 & 4 & 4 & 5 & \\
\hline \multicolumn{2}{|c|}{ ARP } & 568 & 192 & 594 & 1172 & 356 & 1024 & 1280 & \\
\hline \multicolumn{2}{|c|}{ Peringkat ARP } & 14 & 22 & 13 & 8 & 17 & 10 & 7 & \\
\hline
\end{tabular}

Tabel 7 Peringkat Agen Risiko

\begin{tabular}{lll}
\hline No & Kode & Agen Risiko \\
\hline 1 & ARP15 & Kualitas sayur yang tidak sesuai \\
2 & ARP2 & Jumlah menyusut \\
3 & ARP6 & Perjalanan macet atau tersendat \\
4 & ARP9 & Kesalahan penyimpanan \\
5 & ARP1 & Permintaan meningkat \\
6 & ARP10 & Kesalahan packaging \\
7 & ARP23 & Teknik perlakuan atau penanganan sayuran kurang maksimal \\
8 & ARP20 & Human error \\
9 & ARP8 & Sayur rusak dalam perjalanan \\
10 & ARP22 & Ketidakpastian pesanan \\
11 & ARP11 & Penundaan jadwal pengiriman \\
12 & ARP7 & Kurang layaknya transportasi atau kendaraan
\end{tabular}


Berdasarkan tabel tersebut, agen-agen risiko tersebut adalah agen risiko prioritas yang perlu dirancang strategi mitigasi risikonya agar dapat mengurangi, menghindari, memindahkan, hingga menghilangkan risiko yang berpotensi terjadi pada rantai pasok distribusi STA Mantung Kabupaten Malang. Dua belas agen risiko diatas selanjutnya akan dilakukan identifikasi aksi mitigasi risiko yang tepat dengan menggunakan bantuan diagram ishikawa atau diagram fishbone.

Setelah dilakukan analisis menggunakan diagram fishbone atau diagram sebab-akibat, maka diperoleh beberapa strategi atau aksi mitigasi untuk setiap agen risiko.

Langkah selanjutnya dalam HOR fase kedua adalah melakukan penilaian korelasi antara agen risiko yang telah dipilih, dengan strategi mitigisi yang telah diidentifikasi. Sama halnya dengan penilaian korelasi pada HOR fase pertama, kriteria penilaian korelasi kali ini dilakukan dengan skala nilai 0, 1, 3, dan 9. Penilaian tersebut menunjukan seberapa besar hubungan antara agen risiko dengan strategi mitigasi. Nilai 0 artinya tidak ada korelasi, nilai 1 artinya korelasi rendah, nilai 3 artinya korelasi sedang, sedangkan nilai 9 adalah korelasi tinggi. Tidak ada korelasi dapat diartikan sebagai strategi mitigasi tidak berpengaruh terhadap agen risiko, korelasi rendah dapat diartikan sebagai strategi mitigasi kurang efektif jika diterapkan pada agen risiko, korelasi sedang diartikan sebagai strategi mitigasi cukup efektif jika diterapkan pada agen risiko, sedangkan korelasi tinggi artinya strategi mitigasi sangat efektif untuk diterapkan pada agen risiko

Setelah melakukan penilaian korelasi terhadap agen risiko dan strategi mitigasi, langkah selanjutnya yang dilakukan adalah melakukan penilaian tingkat kesulitan aksi mitigasi risiko. Penilaian ini dilakukan untuk mengetahui kemampuan instansi untuk menerapkan strategi mitigasi yang telah teridentifikasi. Penilaian tingkat kesulitan didasarkan pada alasan-alasan yang dibeikan oleh beberapa staf STA Mantung Kabupaten Malang.

Langkah selanjutnya adalah melakukan perhitungan total efektivitas dan total rasio efektivitas kesulitan. Perhitungan total efektivitas (TE) dilakukan untuk mengetahui efektivitas masingmasing strategi mitigasi terhadap agen risiko, sedangkan total rasio efektivitas kesulitan (ETD) untuk melihat tingkat efektivitas dengan melihat kemampuan sumber daya yang ada dalam instansi tersebut.

Setelah melakukan perhitungan TE dan ETD pada HOR fase kedua, maka langkah terakhir pada fase ini adalah memberikan peringkat pada aksi atau strategi mitigasi risiko. 
URL : https://jurnal.machung.ac.id/index.php/kurawal

Tabel 8 HOR Fase 2

\begin{tabular}{llllllllll}
\hline Agen & \multirow{2}{*}{ RRP } & \multicolumn{8}{c}{ Strategi Mitigasi } \\
\cline { 3 - 10 } & & SM1 & SM2 & SM3 & SM4 & SM5 & SM6 & SM7 & SM8 \\
\hline ARP15 & 2156 & 9 & 9 & 0 & 0 & 0 & 1 & 0 & 0 \\
ARP2 & 1908 & 1 & 3 & 9 & 9 & 1 & 3 & 9 & 0 \\
ARP6 & 1820 & 0 & 0 & 9 & 0 & 9 & 9 & 0 & 0 \\
ARP9 & 1536 & 0 & 1 & 9 & 3 & 1 & 1 & 9 & 9 \\
ARP1 & 1421 & 1 & 0 & 0 & 3 & 0 & 0 & 0 & 0 \\
ARP10 & 1404 & 3 & 1 & 9 & 0 & 3 & 3 & 9 & 0 \\
ARP23 & 1280 & 1 & 0 & 3 & 9 & 1 & 1 & 9 & 0 \\
ARP20 & 1172 & 3 & 3 & 0 & 0 & 1 & 1 & 3 & 0 \\
ARP8 & 1056 & 3 & 1 & 9 & 9 & 9 & 9 & 3 & 0 \\
ARP22 & 1024 & 0 & 0 & 0 & 0 & 0 & 0 & 0 & 9 \\
ARP11 & 910 & 0 & 0 & 1 & 9 & 1 & 1 & 0 & 0 \\
ARP7 & 692 & 9 & 0 & 0 & 1 & 0 & 0 & 0 & 0
\end{tabular}

\begin{tabular}{cllllllll} 
Total Efektivitas & 41137 & 32640 & 74266 & 55949 & 36902 & 42874 & 61836 & 23040 \\
\hline Tingkat Kesulitan & 1 & 3 & 3 & 2 & 2 & 3 & 3 & 4 \\
\hline Total Ratio Efektivitas & 41137 & 10880 & 24755 & 27975 & 18451 & 14291 & 20612 & 5760 \\
\hline Peringkat Strategi Mitigasi & 2 & 9 & 4 & 3 & 6 & 7 & 5 & 13
\end{tabular}

\begin{tabular}{cccccccc}
\hline \multirow{2}{*}{ Agen Risiko } & \multirow{2}{*}{ ARP } & \multicolumn{7}{c}{ Strategi Mitigasi } \\
\cline { 3 - 8 } & & SM9 & SM10 & SM11 & SM12 & SM13 & SM14 \\
\hline ARP15 & 2156 & 0 & 0 & 1 & 0 & 3 & 0 \\
ARP2 & 1908 & 3 & 0 & 3 & 0 & 0 & 0 \\
ARP6 & 1820 & 0 & 0 & 9 & 0 & 0 & 0 \\
ARP9 & 1536 & 3 & 3 & 1 & 0 & 0 & 0 \\
ARP1 & 1421 & 0 & 0 & 0 & 0 & 3 & 0 \\
ARP10 & 1404 & 3 & 3 & 1 & 0 & 0 & 0 \\
ARP23 & 1280 & 3 & 3 & 1 & 0 & 0 & 0 \\
ARP20 & 1172 & 9 & 9 & 0 & 0 & 0 & 3 \\
ARP8 & 1056 & 1 & 3 & 9 & 0 & 0 & 0 \\
ARP22 & 1024 & 0 & 0 & 0 & 9 & 9 & 0 \\
ARP11 & 910 & 0 & 0 & 3 & 3 & 0 & 3 \\
ARP7 & 692 & 0 & 0 & 3 & 0 & 0 & 9 \\
\hline Total Efektivitas & 29988 & 26376 & 42790 & 11946 & 10731 & 12474 \\
\hline Tingkat Kesulitan & 3 & 4 & 1 & 1 & 1 & 3 \\
\hline Total Ratio Efektivitas & 9996 & 6594 & 42790 & 11946 & 10731 & 4158 \\
\hline Peringkat Strategi Mitigasi & 11 & 12 & 1 & 8 & 10 & 14 \\
\hline
\end{tabular}




\section{KESIMPULAN DAN SARAN}

Manajemen risiko rantai pasok adalah upaya pengelolaan risiko-risiko yang dapat terjadi pada sebuah aktivitas rantai pasok agar didapatkan rantai pasok yang optimal dan tercegah dari gangguan.

Berdasarkan identifikasi risiko menggunakan metode SCOR, ditemukan lima belas risiko pada rantai pasok distribusi, dengan rincian, tiga risiko pada perencanaan, dua risiko pada pengadaan, enam risiko pada pembuatan, dan empat risiko pada pengiriman. Identifikasi agen risiko ditemukan sebanyak 23 agen risiko penyebab terjadinya risiko yang telah teridentifikasi sebelumnya. Selanjutnya, setelah melakukan pengolahan data menggunakan HOR ditemukan peringkat agen risiko yang terpilih untuk dilakukan strategi mitigasi risiko untuk mengurangi, menghindari, memindahkan, hingga menghilangkan risiko. Berdasarkan pemilihan agen risiko menggunakan diagram pareto, ditemukan dua belas agen risiko yang membutuhkan strategi mitigasi.

Langkah terakhir yang dilakukan dalam pengolahan data manajemen risiko rantai pasok penelitian kali ini adalah melakukan pehitungan total effectiveness dan total effectiveness difficulty ratio pada keempat belas strategi mitigasi. Perhitungan ini dilakukan untuk mengetahui peringkat strategi mitigasi agen risiko.

Saran yang dapat diberikan terkait pada penelitian ini adalah:

1. Pedagang atau pengepul di STA Mantung Kabupaten Malang diharapkan menerapkan strategi mitigasi yang dihasilkan pada penelitian ini. Setelah menerapkan strategistrategi mitigasi tersebut, perlu dilakukan penelitian lebih lanjut untuk mengetahui hasil dari penerapan strategi mitigasi yang ada.

2. Pedagang atau pengepul di STA Mantung Kabupaten Malang diharapkan terus melakukan pembaharuan untuk pengelolaan risiko pada rantai pasok distribusi semua jenis komoditi, terlebih Sawi putih, Kubis, Wortel, Bawang prei, dan Seledri, agar pengelolaan risiko pada rantai pasok menjadi semakin efektif dan efisien, serta sesuai dengan keadaan rantai pasok instansi.

\section{DAFTAR PUSTAKA}

[1] Badariah, N., Surjasa, D., dan Trinugraha, Y. 2011, Analisa Supply Chain Risk Management Berdasarkan Metode Failure Mode and Effects Analysis (FMEA), Tugas Akhir, Universitas Trisakti, Jakarta.

[2] Izharivan, Y. 2014, Center for Risk Management Studies, Ketidakpastian Manajemen Risiko, [Online] Terdapat di: http://crmsindonesia.org/publications/ketidak-pastianmanajemen-risiko/ [diakses 1 Februari 2018]

[3] Mamduh, H.M. 2016, Manajemen Risiko, UPP STIM YKPN, Yogyakarta. 
URL : https://jurnal.machung.ac.id/index.php/kurawal

[4] Zsidisin, G. dan Ritchie, B. 2009, Supply Chain Risk (a handbook of assessment), Spinger, Amerika Serikat.

[5] Zaroni 2015, Supply Chain Indonesia, Manajemen Risiko Rantai Pasok dalam Model SCOR [Online] Terdapat di: http://supplychainindonesia.com/new/manajemen-risikorantai-pasok-dalam-model-scor/ [diakses 20 November 2017]

[6] Hadiguna, R A. 2015, Manajemen Risiko Rantai Pasokan: Pergeseran Orientasi Bersaing Dalam Perspektif Sistem, Tugas Akhir, Universitas Andalas, Padang.

[7] Supply Chain Council 2010, Supply Chain Operations Reference Model, Amerika Serikat

[8] Pujawan, I.N. dan Geraldine, L.H. 2009, Business Process Management, House of Risk: A Model for Proactive Supply Chain Risk Management, Vol. 15 No. 6: 953-967

[9] Tague, N.R. 2005, The Quality Improvement Handbook, $2^{\text {nd }}$ Ed, William A. Tony, Amerika Serikat. pp 117-119, 136-138 